Utah State University

DigitalCommons@USU

Mechanical and Aerospace Engineering Student Mechanical and Aerospace Engineering Student Publications and Presentations

6-8-2020

\title{
Numerical Method for Rapid Aerostructural Design and Optimization
}

Jeffrey D. Taylor

Utah State University, jeffdtaylor3891@gmail.com

Douglas F. Hunsaker

Utah State University, doug.hunsaker@usu.edu

Follow this and additional works at: https://digitalcommons.usu.edu/mae_stures

Part of the Aerospace Engineering Commons, and the Mechanical Engineering Commons

\section{Recommended Citation}

Taylor, J. D., and Hunsaker, D. F., "Numerical Method for Rapid Aerostructural Design and Optimization," AIAA 2020-3175, AIAA Aviation 2020 Virtual Forum, 15-19 June, 2020. (doi:10.2514/6.2020-3175)

This Conference Paper is brought to you for free and open access by the Mechanical and Aerospace Engineering Student Research at DigitalCommons@USU.

It has been accepted for inclusion in Mechanical and Aerospace Engineering Student Publications and Presentations by an authorized administrator of DigitalCommons@USU. For more information, please contactdigitalcommons@usu.edu.

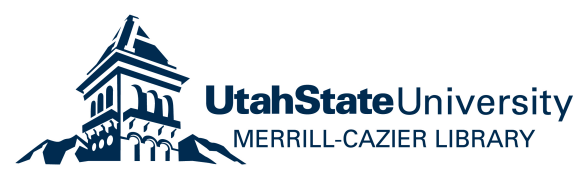




\title{
Numerical Method for Rapid Aerostructural Design and Optimization
}

\author{
Jeffrey D. Taylor ${ }^{*}$ and Douglas F. Hunsaker ${ }^{\dagger}$ \\ Utah State University, Logan, Utah 84322-4130
}

\begin{abstract}
During early phases of wing design, analytic and low-fidelity methods are often used to identify promising design concepts. In many cases, solutions obtained using these methods provide intuition about the design space that is not easily obtained using higher-fidelity methods. This is especially true for aerostructural design. However, many analytic and lowfidelity aerostructural solutions are limited in application to wings with specific planforms and weight distributions. Here, a numerical method for minimizing induced drag with structural constraints is presented that uses approximations that apply to wings with arbitrary planforms and weight distributions. The method is applied to the NASA Ikhana airframe to show how it can be used for rapid aerostructural optimization and design-space exploration. The design space around the optimum solution is visualized, and the sensitivity of the optimum solution to changes in weight distribution, structural properties, wing loading, and taper ratio is shown. The optimum lift distribution and wing-structure weight for the Ikhana airframe are shown to be in good agreement with analytic solutions. Whereas most modern high-fidelity solvers obtain solutions in a matter of hours, all of the solutions shown here can be obtained in a matter of seconds.
\end{abstract}

\section{Nomenclature}

$A \quad=$ beam cross-sectional area

$A_{n} \quad=$ Fourier coefficients in the lifting-line solution for the section-lift distribution, Eq. (1)

$B_{n} \quad=$ Fourier coefficients in the lifting-line solution for the dimensionless section-lift distribution, Eq. (1)

$b \quad=$ wingspan

$C_{\delta} \quad=$ shape coefficient for the deflection-limited design, Eq. (15)

$C_{\sigma} \quad=$ shape coefficient for the stress-limited design, Eq. (5)

$c \quad=$ local wing section chord length

$c_{r} \quad=$ local wing section chord length at the wing root

$c_{t} \quad=$ local wing section chord length at the wing tip

$D_{i} \quad=$ wing induced drag

$E \quad=$ modulus of elasticity of the beam material

$h \quad=$ height of the beam cross-section

I $\quad=$ beam section moment of inertia

$K=$ scaling coefficient in the equation for the fuel distribution, Eq. (22)

$L \quad=$ total wing lift

$\widetilde{L} \quad=$ local wing section lift

$\tilde{M}_{b} \quad=$ local wing section bending moment

$n_{a} \quad=$ load factor, $g$

$n_{g} \quad=$ limiting load factor at the hard-landing design limit

$n_{m} \quad=$ limiting load factor at the maneuvering-flight design limit

\footnotetext{
* PhD Candidate, Mechanical and Aerospace Engineering, 4130 Old Main Hill, AIAA Student Member

${ }^{\dagger}$ Assistant Professor, Mechanical and Aerospace Engineering, 4130 Old Main Hill, AIAA Senior Member
} 


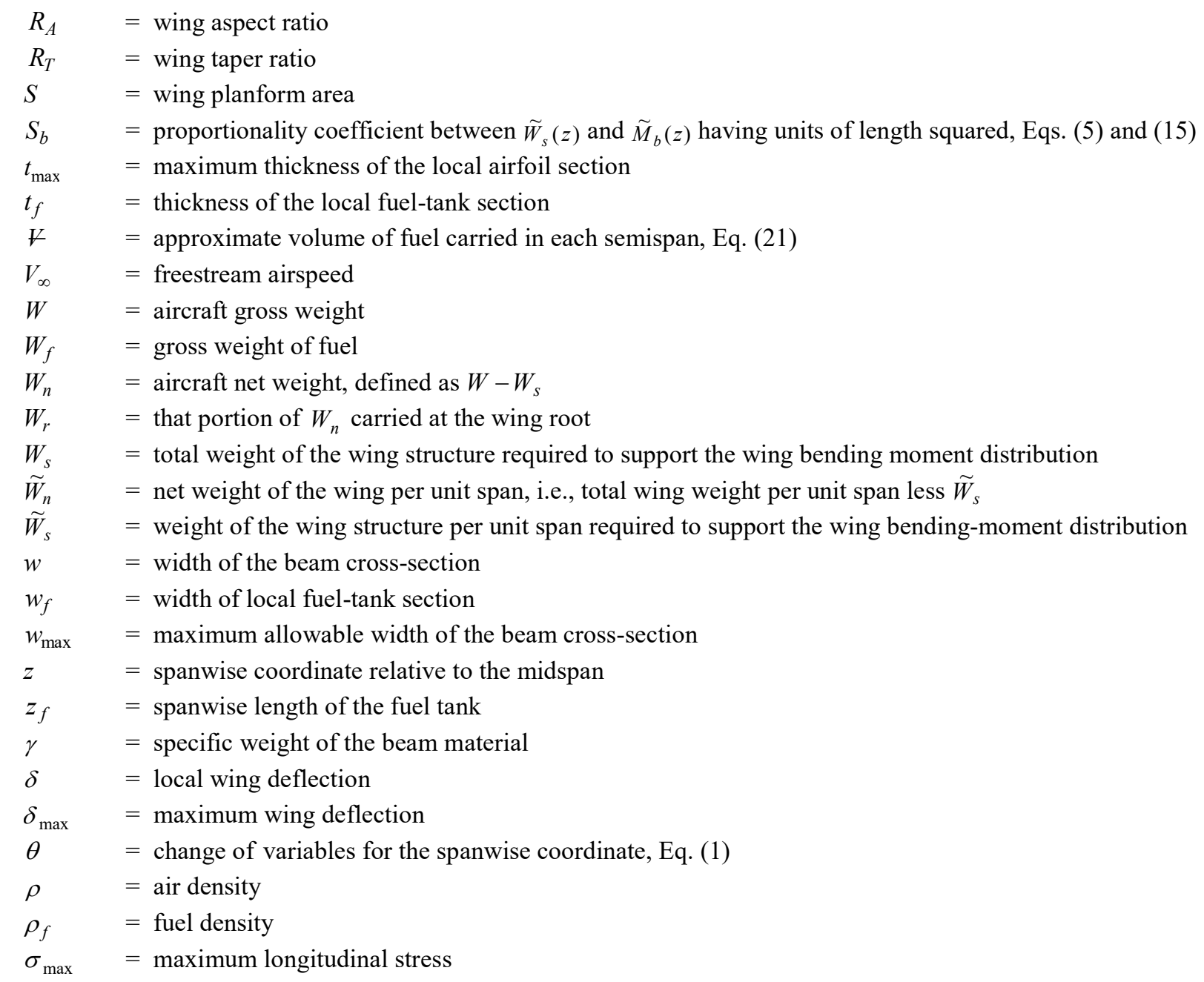

\section{Introduction}

$\mathrm{W}$

HEN designing a wing for minimum drag, low-fidelity tools can be useful for rapid design-space exploration and for gaining important insight and information about how the design variables, parameters, and constraints influence the optimum solution. Designers often rely on rules-of-thumb gained from analytic and low-fidelity numerical solutions during the conceptual and preliminary phases of aircraft design. In many cases, these solutions have been shown to be in good agreement with experimental data and computational fluid dynamics [1-8], while providing significantly more mathematical and physical insight than higher-fidelity models. For example, the wellknown elliptic lift distribution, which minimizes induced drag on an unswept planar wing with fixed weight and wingspan, was first identified from analytic solutions based on lifting-line theory [9,10] by Prandtl [9] and later by Munk [11]. The elliptic lift distribution has since been studied extensively using computational and experimental methods, and it remains a common benchmark in many mid- and high-fidelity computational studies [12-19]. However, it has been shown that the elliptic lift distribution is not the only solution for minimizing drag under all conditions [20-29]. In particular, when structural effects are considered, it has been shown that drag is typically minimized using a non-elliptic lift distribution that depends on the design constraints [12,13,16-18,30-49]. Lowfidelity and analytic aerostructural methods are valuable for identifying these non-elliptic lift distributions and for understanding how structural considerations affect the minimum-drag solution.

There are many mid- and high-fidelity computational methods for minimizing drag under structural constraints, including those shown in Refs. [12,13,16-18,30-38]. Many of these methods require time-consuming and computationally expensive coupling between high-fidelity aerodynamic and structural solvers. However, there are relatively few studies that approach this multidisciplinary problem from an analytic or low-fidelity point of view 
[39-49]. Prandtl seems to be the first do so, and in 1933, he identified a bell-shaped lift distribution that minimizes induced drag on a rectangular wing with fixed gross weight and moment of inertia of gross weight [39]. Since then, others have taken approaches similar to Prandtl to minimize induced drag under different constraints [39-48]. For example, Jones [40] sought to minimize induced drag under the constraints of fixed gross lift and root bending moment in cruise. Pate and German [41] constrained the root bending moment at a given off-design lift coefficient. DeYoung [42] replaced Jones' root-bending-moment constraint with a constraint on the bending moment at a prescribed spanwise location. Jones and Lasinski [43] later constrained the integrated bending moment. Klein and Viswanathan $[44,45]$ considered both root and integrated bending moment [44] and included the effects of the wing-structure weight [45]. Löbert [46] introduced a constraint based on the ratio of the bending-moment distribution and the wing-section thickness. However, it appears that none of these studies show how the planform shape affects the wing-structure weight, and only Klein and Viswanathan [45] directly accounted for the effects of the wing weight distribution on the bending moments.

More recently, Phillips et al. [47,48] and Taylor and Hunsaker [49] relaxed many of Prandtl's assumptions and extended his approach to account for the effects of the planform shape on the wing-structure weight and the effects of the wing weight distribution on the bending moments. They identified lift distributions that minimize induced drag under constraints of fixed gross weight [47], fixed net weight [48], fixed wing loading [47,48], and fixed stall speed [48]. However, in order to obtain analytic solutions, Phillips et al. [47,48] limited their results to rectangular wings with a single ideal weight distribution, and Taylor and Hunsaker [49] limited their results to linearly and elliptically tapered wings with the same ideal weight distribution. In fact, all of the analytic studies discussed here are limited in application to wings with specific planforms and/or weight distributions.

The purpose of this paper is to present a low-fidelity numerical method that extends the work of Phillips et al. $[47,48]$ and Taylor and Hunsaker [49] to more practical aircraft configurations with arbitrary planforms and weight distributions. We will apply the method to a high-endurance unmanned aircraft configuration to demonstrate how it can be used for rapid conceptual design and for gaining intuition about the aerostructural design space. The present work builds on the approach taken by Prandtl [39] and Phillips et al. [47,48]. Therefore, we will first briefly review the work of these authors.

\section{Analytical Foundation}

Using Prandtl's classical lifting-line theory [9,10], the dimensionless spanwise section-lift distribution on a finite wing with no dihedral or sweep immersed in a uniform flow can be described using a Fourier series of the form [47]

$$
\frac{b \widetilde{L}(\theta)}{L}=\frac{4}{\pi}\left[\sin (\theta)+\sum_{n=2}^{\infty} B_{n} \sin (n \theta)\right] ; \quad B_{n} \equiv \frac{A_{n}}{A_{1}}, \quad \theta \equiv \cos ^{-1}(-2 z / b)
$$

where $B_{n}$ are the dimensionless Fourier coefficients. The lift distribution is, in general, linked to the wing planform and the wing twist. However, below stall, any lift distribution can be produced by a twisted wing of any planform, provided that the correct twist distribution is used [50]. Therefore, in the development presented in this paper, the lift distribution and the planform are treated as independent parameters, related through the wing twist. Moreover, this study focuses on minimizing induced drag. Therefore, we will neglect the effects of viscous drag.

In steady-level flight, the total lift, $L$, must equal the gross weight, $W$. Using this relation and the definition for drag coefficient, the induced drag predicted by Prandtl's classical lifting-line theory in steady-level flight is

$$
D_{i}=\frac{2(W / b)^{2}}{\pi \rho V_{\infty}^{2}}\left(1+\sum_{n=2}^{\infty} n B_{n}^{2}\right)
$$

Equation (2) reveals that minimizing induced drag for a given flight condition is a variational problem involving weight, wingspan, and lift distribution. For a fixed ratio of weight to wingspan, Eq. (2) is minimized with a lift distribution having $B_{n}=0$ for all $n>1$, which gives the well-known elliptic lift distribution. If weight and wingspan are allowed to vary, the elliptic lift distribution no longer gives an absolute minimum in induced drag. From Eq. (2), it is evident that induced drag can be reduced by increasing wingspan or decreasing wing weight. However, as wingspan increases, the weight of the wing structure required to support the bending moments also increases, which increases the total weight. Because of the tradeoff between wing-structure weight and wingspan, there exists some 
optimal wingspan that minimizes induced drag for a given lift distribution. Furthermore, certain lift distributions that shift lift inboard toward the wing root can alleviate bending moments near the wingtips, allowing a higher wingspan with no increase in wing-structure weight. Therefore, to fully minimize Eq. (2) for a given flight condition, the weight, wingspan, and lift distribution must all be considered.

Prandtl analytically solved this variational problem in 1933 [39] and identified a bell-shaped lift distribution having $B_{2}=0, B_{3}=-1 / 3$, and $B_{n}=0$ for $n>3$ that minimizes induced drag for rectangular wings under constraints of fixed gross weight and moment of inertia of gross weight. Prandtl's 1933 lift distribution [39] was obtained under the assumption that the wing-structure weight distribution $\widetilde{W}_{s}(z)$ is proportional to the wing bending-moment distribution $\tilde{M}_{b}(z)$ at each spanwise location and that the proportionality coefficient $S_{b}$ between the wing-structure weight distribution and the bending-moment distribution is spanwise invariant, i.e.,

$$
\widetilde{W}_{s}(z)=\frac{\tilde{M}_{b}(z)}{S_{b}}
$$

This assumption implies that the geometric and structural properties of the wing structure are consistent across the span. However, the wing-structure geometry is typically a function of the wing thickness and chord distribution. Therefore, Prandtl's assumption is best matched by a rectangular wing with a constant thickness-to-chord ratio [39]. Prandtl also neglected the effect of the wing weight on the wing bending moments by assuming that the bendingmoment distribution is a function of the lift distribution alone. Under the constraints of these assumptions, Prandtl's 1933 lift distribution allows an increase in wingspan of $22.5 \%$ and a reduction in induced drag of $11.1 \%$ when compared to that of the elliptic lift distribution with the same wing-structure weight.

Whereas Prandtl assumed that the bending moments are only a function of the lift distribution, Phillips et al. [47] pointed out that at each spanwise location, the wing bending moments are a function of the lift distribution, the netweight distribution $\widetilde{W}_{n}(z)$ of all non-structural components carried in the wing, and the wing-structure weight distribution $\widetilde{W}_{s}(z)$ according to the relation [47]

$$
\widetilde{M}_{b}(z)=\int_{z^{\prime}=z}^{b / 2}\left[\widetilde{L}\left(z^{\prime}\right)-n_{a} \widetilde{W}_{n}\left(z^{\prime}\right)-n_{a} \widetilde{W}_{s}\left(z^{\prime}\right)\right]\left(z^{\prime}-z\right) d z^{\prime}, \quad \text { for } z \geq 0
$$

where $n_{a}$ is the load factor. The wing structure must be designed to support the bending moments during a high-load maneuver with a positive load limit $n_{m}$ and during a hard landing with a negative load limit $n_{g}$. For the stress-limited design of a wing, minimum wing-structure weight is achieved when the structure is designed such that the local stress at each spanwise location is equal to the maximum allowable stress $\sigma_{\max }$. Using this constraint and assuming that all of the wing bending moments are supported by a single, vertically-symmetric beam in pure bending, the weight of the wing structure required to support the bending moments can be written [47]

$$
\widetilde{W}_{s}(z)=2 \int_{0}^{b / 2} \frac{\left|\tilde{M}_{b}(z)\right|}{S_{b}(z)} d z ; \quad S_{b}(z)=\frac{C_{\sigma}\left[t_{\max }(z) / c(z)\right] c(z) \sigma_{\max }}{\gamma}, \quad C_{\sigma}=\frac{2 I\left(h / t_{\max }\right)}{A h^{2}}
$$

where $c(z)$ is the section chord-length distribution, $\gamma$ is the specific weight of the beam material, $t_{\max } / c$ is the maximum-thickness-to-chord ratio of the local airfoil section, and $C_{\sigma}$ is the beam shape factor for the stress-limited design. A list of shape factors for common beam cross sections is given in [47]. For deflection-limited designs, the maximum allowable stress can be related to the maximum deflection, and Eq. (5) can be rewritten as [47]

$$
\tilde{W}_{s}(z)=2 \int_{0}^{b / 2} \frac{\left|\tilde{M}_{b}(z)\right|}{S_{b}(z)} d z ; \quad S_{b}(z)=\frac{C_{\delta} E\left[t_{\max }(z) / c(z)\right]^{2} \delta_{\max }}{\gamma(W / S)^{2}} \frac{W^{2}}{b^{4}}, \quad C_{\delta}=\frac{8 I\left(h / t_{\max }\right)^{2}}{A h^{2}}
$$

where $C_{\delta}$ is the beam shape factor for the deflection-limited design.

The total weight of the wing is the sum of the wing-structure weight and the net weight of all non-structural components, i.e., 


$$
W=W_{s}+W_{n}
$$

where the wing-structure weight $W_{s}$ is found by integrating Eq. (5) or (6). The net weight $W_{n}$ is found from the relation

$$
W_{n}=W_{r}+\int_{z=-b / 2}^{b / 2} \widetilde{W}_{n}(z) d z
$$

where $W_{r}$ is the portion of the net weight carried at the wing root. Under these assumptions, Phillips et al. [47] have shown that the bending moments are minimized when the net weight is distributed according to the weight constraints given by

$$
\begin{gathered}
\widetilde{W}_{n}(z)=\left(W-W_{r}\right) \frac{\widetilde{L}(z)}{L}-\widetilde{W}_{s}(z) \\
W_{r}=\frac{n_{g}-1}{n_{m}+n_{g}} W
\end{gathered}
$$

For a rectangular wing having the weight distribution given in Eq. (9), the proportionality coefficient $S_{b}$ is spanwise invariant, and Eqs. (5) and (6) can be evaluated analytically. Using the result of Eqs. (5) and (6) and applying Eq. (7) in Eq. (2), Phillips et al. [48] showed that, if wing loading is fixed, induced drag is minimized with a lift distribution having $B_{2}=0, B_{3}=-3 / 8+\sqrt{9 / 64-1 / 12}$, with $B_{n}=0$ for $n>3$ for the stress-limited design and $B_{2}=0$, $B_{3}=-3 / 7+\sqrt{9 / 49-1 / 21}$, with $B_{n}=0$ for $n>3$ for the deflection-limited design. However, Phillips et al. [47,48] only considered the case of a rectangular wing with the weight distribution given in Eq. (9). As will be shown, if the planform is non-rectangular or a weight distribution other than that given in Eq. (9) is used, the integrals in Eqs. (4), (5), and (6) and the maximum deflection in Eq. (6) often must be evaluated numerically. In this paper, we extend the work of Phillips et al. [47,48] and present a method for minimizing induced drag for wings with non-rectangular planforms and weight distributions other than that given in Eq. (9). However, it should be remembered that the present method maintains the assumptions associated with lifting-line theory, including a planar wing with zero sweep and moderate to high aspect ratio. For other wing configurations, modifications to this method may be needed.

\section{Wing-Structure Weight and Induced Drag}

For the stress-limited design of a wing with a non-rectangular planform and a weight distribution other than that given in Eq. (9), numerically evaluating the integrals in Eqs. (4) and (5) is straightforward. For any given flight condition, the wing section bending moments, as given by Eq. (4), are a function of the lift distribution, net-weight distribution, and wing-structure weight distribution. However, Eq. (5) shows that the wing-structure weight distribution is dependent on the bending-moment distribution. Because of this interdependence between the section bending moments and the wing-structure weight, if any weight distribution other than that given in Eq. (9) is used, an iterative method is required to compute the wing-structure weight. The induced drag can be found by using the wingstructure weight and Eq. (7) in Eq. (2). An implementation of this iterative process is given by Taylor et al. [51] for the stress-limited design.

For the deflection-limited design, if the beam is designed with minimum allowable wing-structure weight, the deflection of the beam can be found using the relation [47]

$$
\frac{d^{2} \delta}{d z^{2}}=\frac{2 \sigma_{\max }}{\operatorname{Eh}(z)}
$$

where $E$ is the modulus of elasticity of the beam material. For any spanwise-symmetric load distribution, the boundary conditions on Eq. (11) are 


$$
\delta(0)=0,\left.\quad \frac{d \delta}{d z}\right|_{z=0}=0
$$

Equations (11) and (12) constitute a boundary-value problem from which the beam deflection can be found. Integrating Eq. (11) subject to Eq. (12), the deflection at any spanwise location $z_{0}$ becomes

$$
\delta\left(z_{0}\right)=\frac{2 \sigma_{\max }}{E} \int_{0}^{z_{0}} \int_{0}^{z} \frac{1}{h\left(z^{\prime}\right)} d z^{\prime} d z
$$

If both maneuvering and hard-landing design limits are considered, maximum deflection always occurs at the wingtips. Using Eq. (13), the deflection at the wingtip is found to be

$$
\delta_{\max }=\frac{2 \sigma_{\max }}{E} \int_{0}^{b / 2} \int_{0}^{z} \frac{1}{h\left(z^{\prime}\right)} d z^{\prime} d z
$$

Equation (14) relates the maximum allowable deflection with the maximum stress at each section for a given beamheight distribution, $h(z)$. Because airfoil thickness is typically a fraction of the chord length, the beam-height distribution is typically related to the chord distribution. For certain beam-height or chord distributions, the integral in Eq. (14) can be evaluated analytically [47]. However, if the beam-height or chord distribution is an arbitrary function of spanwise location, Eq. (14) must be evaluated using numerical methods.

Using Eq. (14) to replace $\sigma_{\max }$ in Eq. (5), the wing-structure weight required to support the bending moments for the deflection-limited design can be written

$$
W_{s}(z)=2 \int_{0}^{b / 2} \frac{\left|\widetilde{M}_{b}(z)\right|}{S_{b}(z)} ; \quad S_{b}(z)=\frac{C_{\delta} E\left[t_{\max }(z) / c(z)\right] c(z) \delta_{\max }}{8 \gamma \int_{0}^{b / 2} \int_{0}^{z}\left[t_{\max }\left(z^{\prime}\right) / c\left(z^{\prime}\right)\right]^{-1} c\left(z^{\prime}\right)^{-1} d z^{\prime} d z}, \quad C_{\delta}=\frac{8 I\left(h / t_{\max }\right)^{2}}{A h^{2}}
$$

Like Eq. (5), Eq. (15) shows that the wing-structure weight for the deflection-limited design is also coupled with the bending-moment distribution. Thus, an iterative solver is needed to solve for the wing-structure weight for the deflection-limited design. The induced drag is found by using the wing-structure weight from Eq. (15) and Eq. (7) in Eq. (2).

If Eq. (5) predicts a wing-structure weight that is greater than that predicted by Eq. (15), the design is stress limited; if Eq. (15) gives a value greater than Eq. (5), the design is deflection limited. Because the limiting constraint is highly dependent on the design parameters, both stress and deflection limits must be considered at each spanwise location.

\section{Numerical Methodology}

Here, we present a method for iteratively solving for the wing-structure weight and describe how it can be used in an optimization framework to minimize induced drag. This method is similar to that given by Taylor et al. [51] for the stress-limited design, but here we will include the deflection-limited design and several additional constraints that were not considered in Ref. [51].

\section{A. Solving for Wing-Structure Weight}

For this study, a simple fixed-point iteration scheme is used to solve for the wing-structure weight and bendingmoment distribution. An initial guess for the wing-structure weight is used in Eq. (4) to calculate the section bendingmoment distribution for both the maneuvering and hard-landing limits. At each section, the limit that produces a higher-magnitude section bending moment is the design limit. This section bending moment is used in Eqs. (5) and (15) to predict the section wing-structure weight for the stress-limited and deflection-limited designs. At each section, the design that requires greater wing-structure weight is the limiting design, and the corresponding wing-structure weight is used. This value is then passed back as the guess for the next iteration, and the process is repeated until the 
wing-structure weight converges within some specified tolerance. For the purposes of this study, an initial guess of $\widetilde{W}_{s}(z)=0$ provides good results. The process can be summarized as follows:

1. Input $b, \widetilde{L}(z) / L, W_{r}, \widetilde{W}_{n}(z), c(z), t_{\max }(z) / c(z), \gamma, E, \sigma_{\max }, \delta_{\max }, n_{m}, n_{g}, C_{\sigma}$, and $C_{\delta}$.

2. Calculate the total weight using Eq. (7). For the initial guess, use $\widetilde{W}_{s}(z)=0, W_{s}=0$.

3. Calculate the total net weight using Eq. (8).

4. Calculate the maneuvering and hard-landing bending-moment distributions using Eq. (4).

5. Using the higher-magnitude section bending moment from step 3 in Eqs. (5) and (15), calculate the wingstructure weight distribution for the stress-and deflection-limited designs.

6. Calculate the total wing-structure weight by integrating either Eq. (5) or (15).

7. Repeat steps 2 through 6 until the wing-structure weight has converged to within a specified tolerance.

Once the wing-structure weight is known, the induced drag is calculated using Eq. (2). A schematic of the process is shown in Fig. 1. Note that after the first iteration, step 2 is only required if the net weight is a function of the wingstructure weight, as it is in Eq. (9). In this paper, this special case will be used for benchmarking the wing-structure weight solver against analytic solutions. However, it should be remembered that Eq. (9) is not meant to represent any physical weight distribution, and for most practical aircraft configurations, step 2 is not needed after the first iteration.

For wings with arbitrary chord distribution, thickness distribution, or net-weight distribution, the prediction of the wing-structure weight requires the numerical evaluation of multiple integrals. In general, any high-order integration scheme can be used to obtain valid results. However, in this study, the composite Simpson's rule is used to evaluate all integrals. The wing is discretized with nodes clustered near the wingtips using the cosine clustering scheme given in Eq. (1), with even spacing in $\theta$. The resulting discretization is shown in Fig. 2.

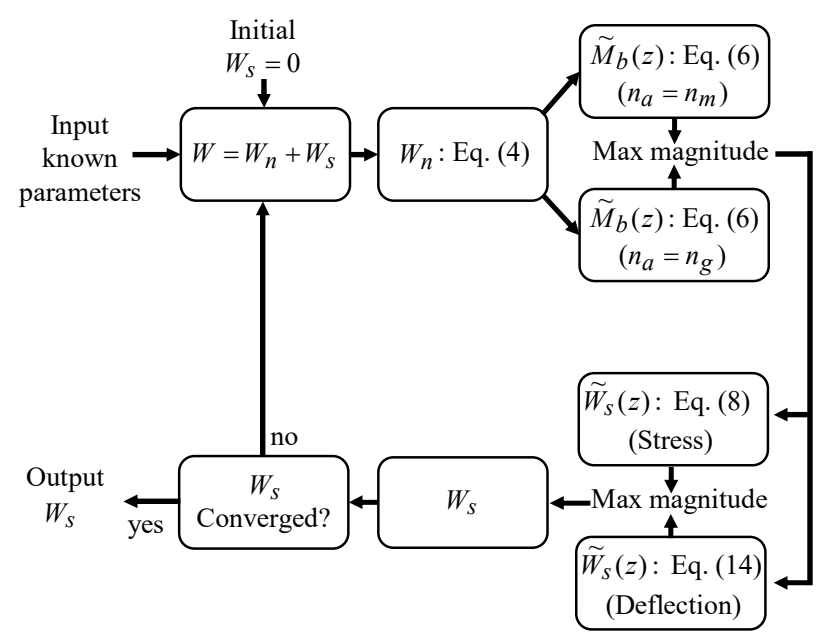

Fig. 1 Schematic of the iterative wing-structure weight solver.

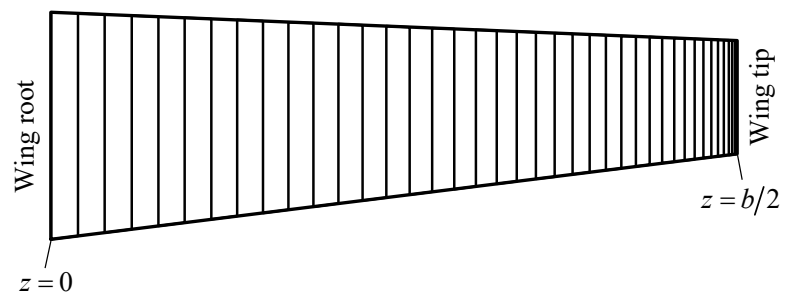

Fig. 2 Discretization of a tapered semispan with 40 nodes and cosine clustering near the wing tip. 
In order to ensure grid convergence, the iterative wing-structure solver was used to predict the wing-structure weight required to support the elliptic lift distribution for a wing with the parameters $R_{T}=0.5, b=66.0 \mathrm{ft}$, $S=267.3 \mathrm{ft}^{2}, t / c=0.1875, C_{\sigma}=0.165, C_{\delta}=0.653, \sigma_{\max }=25 \times 10^{3} \quad \mathrm{psi}, \quad \delta_{\max }=3.5 \quad \mathrm{ft}, \quad E=10.0 \times 10^{6} \mathrm{psi}$, $\gamma=0.10 \mathrm{lbf} / \mathrm{in}^{3}, W_{r}=4500 \mathrm{lbf}, W_{n}=7500 \mathrm{lbf}, n_{m}=n_{g}=3.75$, and the weight distribution given by Eq. (9). Results were compared using grids with node counts ranging between 10 and 1280, and Richardson Extrapolation was used to project a fully-converged value. Figure 3 shows the results of this study. With as few as 160 nodes, the wingstructure weight predicted by the iterative algorithm falls within $0.003 \%$ of the extrapolated value. Therefore, 160 nodes will be used for all subsequent results. Above 40 nodes, the method shows second-order convergence.

The wing-structure solver was also benchmarked against the analytic solutions found by Phillips et al. [47] using the example wing configuration described above with a taper ratio of $R_{T}=1$. The total wing-structure weight calculated by the solver matches the analytic solution to within $0.0025 \%$. Figure 4 shows that the wing-structure weight distribution predicted by the solver is in good agreement with the analytic solution.

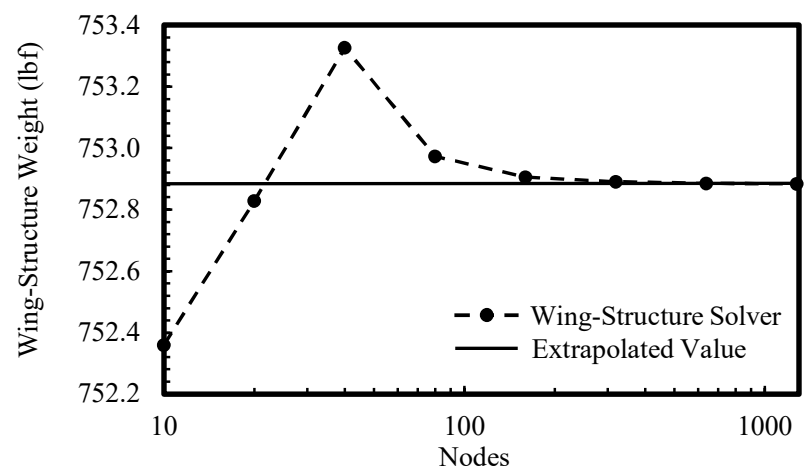

Fig. 3 Grid resolution results for the iterative wing-structure weight solver.

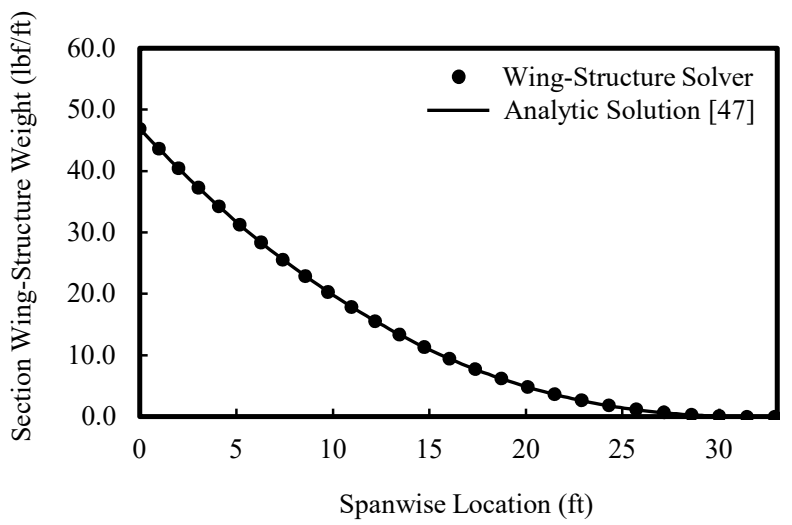

Fig. 4 Comparison of the wing-structure weight predicted by the numerical wing-structure weight solver and the analytic solution from Ref. [47].

\section{B. Minimizing Induced Drag in an Optimization Framework}

In order to minimize induced drag, the induced drag from the wing-structure solver is used as an objective function in an optimization framework similar to that shown in Fig. 5. The induced drag is a function of the lift distribution, wingspan, and weight. It has been shown that the weight is a function of the net-weight distribution, proportionality coefficient, and several other parameters. Any of these parameters could be used as design variables. However, in this study, we will use the lift distribution and wingspan as design variables, since both variables directly affect the induced drag and wing-structure weight. 


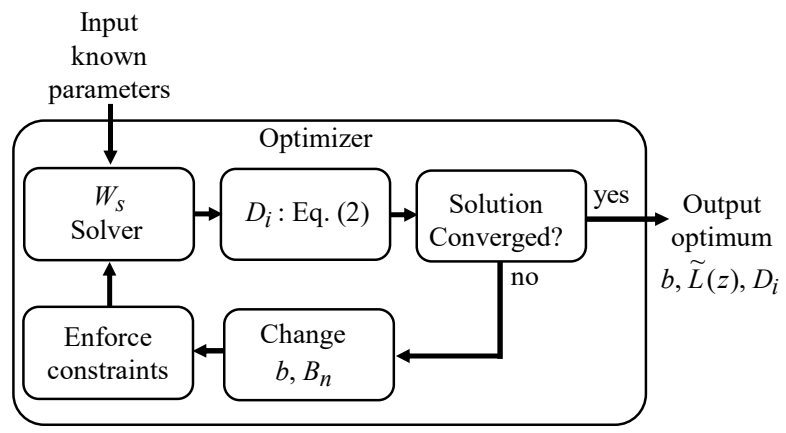

Fig. 5 Example optimization framework for minimizing induced drag using wingspan and lift distribution.

As shown by Phillips et al. [47,48], the choice of design constraints can have a significant impact on the minimuminduced-drag solution. The methods presented in this paper are general enough to accommodate a variety of constraints, including those used in many of the studies mentioned in the Introduction. In the following section, we describe how several example design constraints can be implemented within the optimization framework shown in Fig 5.

\section{Example Constraints}

Throughout the development in the previous sections, the lift distribution is assumed to be all positive and spanwise-symmetric. Thus, any lift distribution chosen by the optimizer must also be all-positive and spanwisesymmetric. The lift distribution can be constrained to be all-positive by ensuring that the optimizer only chooses values for $B_{n}$ that produce a lift distribution with positive lift at every spanwise location. This can be enforced using an equality constraint on the minimum section-lift value. The lift distribution can be made spanwise-symmetric by setting all even Fourier coefficients from Eq. (1) identically to zero.

Phillips et al. [47,48] enforced constraints of fixed gross weight, fixed net weight, and fixed wing loading. The constraint of fixed net weight can be imposed by scaling the net-weight distribution at each optimizer iteration such that Eq. (8) is satisfied for a given value of $W_{n}$. The constraint of fixed gross weight is most easily imposed by scaling the net-weight distribution to satisfy the relation

$$
\frac{1}{W-W_{s}-W_{r}} \int_{0}^{b / 2} \widetilde{W}_{n}(z)=1
$$

Because the gross weight is a function of both the net weight and the wing-structure weight, the net weight should be scaled to satisfy Eq. (16) at the end of each iteration of the wing-structure weight solver in order to ensure that the solver converges on the correct wing-structure weight for the specified gross weight. The constraint of fixed wing loading can be implemented by scaling the chord distribution at each optimizer iteration such that

$$
\frac{(W / S)}{W} \int_{0}^{b / 2} c(z) d z=1
$$

It is also useful to constrain the spar dimensions such that the spar fits within the local airfoil section. For a given beam cross-section, the cross-sectional area roughly scales with the product of width $w$ and height $h$ and the moment of inertia roughly scales with the product of width $w$ and height cubed $h^{3}$. Hence, if the ratio $h / t_{\max }$ in Eqs. (5) and (15) is constant across the wingspan, it is also convenient hold $C_{\sigma}$ and $C_{\delta}$ constant across the span. Moreover, in order for the beam to fit inside the airfoil, the ratio $h / t_{\max }$ must be less than one, and a constraint must be placed on beam width. In general, a geometric beam-width constraint can only be evaluated after the beam width has been determined in conjunction with all other beam dimensions. However, for a rectangular beam with fixed $\left(h / t_{\max }\right)$, the width can be determined using the relation $A(z)=w(z) h(z)=w(z)\left[t_{\max }(z) / c(z)\right]\left(h / t_{\max }\right)$ in the expression $\widetilde{W}_{s}(z)=\gamma A(z)$ to give 


$$
\widetilde{W}_{s}(z)=\gamma c(z) w(z)\left[t_{\max }(z) / c(z)\right]\left(h / t_{\max }\right)
$$

Because the size of the local airfoil section scales with chord length, it is convenient to specify a width constraint in terms of a ratio of maximum allowable width $w_{\max }$ to chord length $c$. Therefore, the maximum allowable width-tochord ratio can be found by rearranging Eq. (18) to give

$$
w_{\max } / c(z) \geq \frac{\widetilde{W}_{s}(z)}{\gamma\left[t_{\max }(z) / c(z)\right]\left(h / t_{\max }\right) c(z)^{2}}
$$

It should be remembered that the constraints described here are not the only useful constraints for wing design. However, those included here will be used in the following section to compare the results obtained using the numerical methods described in this section to the solutions of Phillips et al. [47,48] and Taylor and Hunsaker [49].

\section{Results}

As an example of minimizing induced drag for a wing with a non-rectangular planform and a net-weight distribution other than that given in Eq. (9), consider the NASA Ikhana airframe. Many of Ikhana's geometric and weight parameters can be obtained or inferred from publicly available data [52-55]. For instance, Ikhana has a tapered wing with a wingspan $b=66 \mathrm{ft}$. The tip airfoil has a chord length $c_{t}=2.4 \mathrm{ft}$ and max thickness $t_{\max }=5.4$ in. At the wing-fuselage junction, the airfoil has a chord length $c_{r}=5.4 \mathrm{ft}$ and max thickness of about $t_{\max }=12.15$ in. [54]. Using these values, the thickness-to-chord ratio of both airfoils is $t / c=0.1875$. From fuselage to wingtip, each semispan is approximately $30 \mathrm{ft}$. Since we do not include the aerodynamic effects of the fuselage, the wing geometry is extrapolated to the fuselage centerline, which results in a semispan of $33 \mathrm{ft}$. Assuming that the wing is linearly tapered, the chord distribution can be written as

$$
c(z)=c_{r}\left[1-\left(1-R_{T}\right)|2 z / b|\right]
$$

Extrapolating the chord distribution from known tip- and root-chord data, Eq. (20) gives a root chord of $c_{r}=5.7 \mathrm{ft}$ at the fuselage centerline. Using this value with the wingspan and tip chord, the total area for the extrapolated wing is $S=267.3 \mathrm{ft}^{2}$, the aspect ratio is $R_{A}=16.296$, and the taper ratio is $R_{T}=0.421$.

The Ikhana airframe has an empty weight of $3700 \mathrm{lbf}$, a maximum payload of $2300 \mathrm{lbf}$, and a maximum fuel load of $4000 \mathrm{lbf}$. The payload can be distributed with up to $800 \mathrm{lbf}$ in the nose of the aircraft and up to $2300 \mathrm{lbf}$ carried externally on the wings [54]. The distribution of weight in the wings must be inferred. Assuming that all of the fuel is carried in bladders in the wings and that the cross-sectional area of the fuel bladders can be approximated by an ellipse with a constant thickness-to-chord ratio and a constant width-to-chord ratio, as shown in Fig. 6, the volume of a fuel bladder beginning at the wing root can be approximated as

$$
\forall=\frac{\pi}{16}\left[\left(t_{f} / c\right) c(z)+\left(w_{f} / c\right) c(z)\right]^{2} \int_{0}^{z_{f}} c(z)^{2} d z
$$

where $z_{f}$ is the spanwise length of the fuel bladder, $t_{f} / c$ is the thickness-to-chord ratio of the elliptic cross section, and $w_{f} / c$ is the width-to-chord ratio of the elliptic cross section. Assuming that the fuel bladders have sufficient volume to carry $2000 \mathrm{lbf}$ of fuel in each semispan, and assuming that the density of fuel is $\rho_{f}=0.029 \mathrm{lbf} / \mathrm{in}^{3}$, the thickness-to-chord ratio of the fuel bladder is $t_{f} / c=0.16875$, and the width-to-chord ratio is $w_{f} / c=0.45$, the volume of fuel in each semispan can be approximated as $68,966 \mathrm{in}^{3}$. Using this value in Eq. (21) and solving for $z_{f}$ gives a spanwise bladder length of $328.9 \mathrm{in}$. Therefore, in order to have sufficient volume to hold $4000 \mathrm{lbf}$, the fuel bladders must extend to about $83.1 \%$ semispan. 


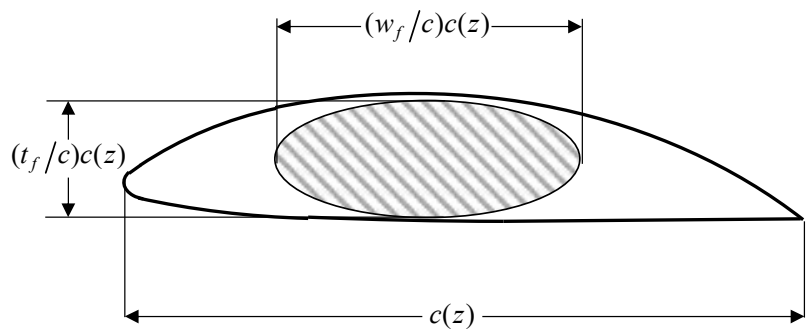

Fig. 6 Geometric approximation of Ikhana fuel bladder cross-sectional area.

From Eq. (21), we see that if the fuel bladder cross-sectional area is approximated as an ellipse, the net-weight distribution is proportional to the square of the chord, i.e.,

$$
\widetilde{W}_{n}(z)=K c(z)^{2}
$$

where $K$ is a scaling constant that depends on the length of the fuel bladder and the weight of the fuel carried in the wing. Using Eq. (22) in Eq. (8) gives a relationship that can be solved to find the value of $K$ for a fuel bladder that extends to $83.1 \%$ semispan with a given fuel weight $W_{f}$, i.e.,

$$
W_{f}=2 K \int_{0}^{0.831 b / 2} c(z)^{2} d z
$$

A generic instrumentation pod weighing $500 \mathrm{lbf}$ [55] is also sometimes mounted on the wing at a hard point outboard of the wing root.

For the purposes of this study, we will consider two example configurations for the NASA Ikhana airframe in steady level flight at sea level with a typical cruise velocity of $287 \mathrm{ft} / \mathrm{s}$ [53]. The first configuration has $3000 \mathrm{lbf}$ of fuel distributed according to Eq. (22) in fuel bladders spanning 83.1\% semispan with no instrumentation pod. Using a fuel weight of $3000 \mathrm{lbf}$ in Eq. (23) with a wingspan of $b=66 \mathrm{ft}$ gives a scaling constant $K=2.8212$. The second example configuration includes a generic instrument pod mounted on each wing at hard points located at $25 \%$ semispan that each cover $1 \mathrm{ft}$ spanwise. In order to maintain the same fixed net weight as the no-pod configuration, the fuel weight is reduced to $2000 \mathrm{lbf}$ for this configuration. Using this fuel weight, Eq. (23) gives a scaling constant $K=1.8808$. Using this value in Eq. (22) and adding the weight distribution of the instrumentation pod gives the netweight distribution shown in Fig. 7. All other parameters for both configurations are given in Table 1 . Note that many of the structural parameters for the Ikhana airframe are not publicly available. Therefore, the values for $C_{\sigma}$ and $C_{\delta}$ in Table 1 were found using Eqs. (5) and (15) for a beam with a rectangular cross section, and the values for $\sigma_{\text {max }}, E$, and $\gamma$ were selected to be conservative. The maneuvering and hard-landing load limits represent a typical load limit of $2.5 \mathrm{~g}$ with a safety factor of 1.5 . The maximum deflection is just over $10 \%$ of the semispan, which is reasonable for a high-aspect-ratio wing. However, it will be shown that results are sensitive to changes in this parameter.

It has been shown that wings with taper ratios near $R_{T}=0.4$ produce a nearly elliptic lift distribution with no aerodynamic or geometric twist [56,57]. Because the Ikhana airframe has a taper ratio of $R_{T}=0.421$, we will use the elliptic lift distribution for the baseline design. Using the elliptic lift distribution, the wing-structure solver shown in Fig. 1 predicts a wing-structure weight of $1008.4 \mathrm{lbf}$ and induced drag of $54.040 \mathrm{lbf}$ for the no-pod configuration. The total weight is $8508.4 \mathrm{lbf}$, and the wing loading is 31.831 . For the pod configuration, the wing-structure solver predicts a wing-structure weight of $1080.5 \mathrm{lbf}$, giving a total weight of $8580.5 \mathrm{lbf}$ and a wing loading of 32.101 . The induced drag is 54.959 lbf. A summary of the results for the baseline design is included in Table 2. 


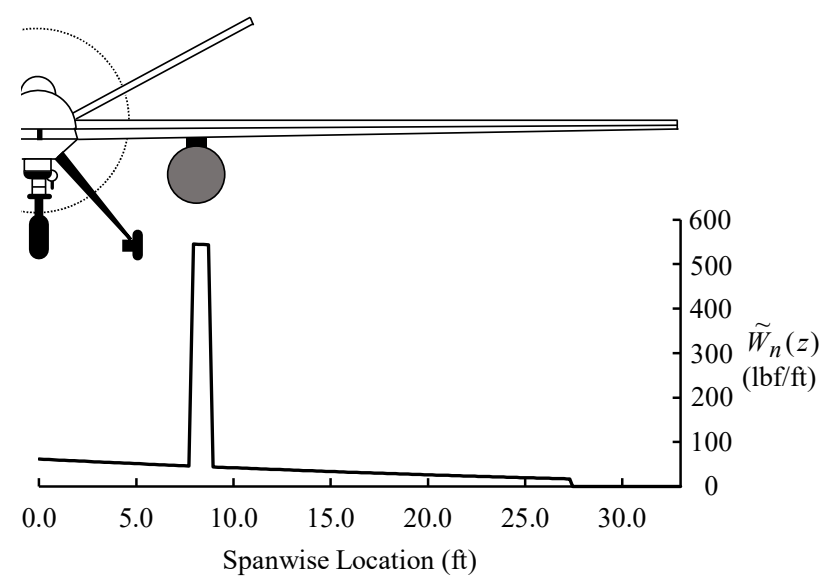

Fig. 7 Example net-weight distribution for the Ikhana wing carrying $2000 \mathrm{lbf}$ of fuel and a generic instrumentation pod.

Table 1 Example Specifications for the Ikhana airframe

\begin{tabular}{ll}
\hline \hline$S\left[\mathrm{ft}^{2}\right]$ & 267.3 \\
$B[\mathrm{ft}]$ & 66 \\
$R_{T}$ & 0.421 \\
$t / c$ & 0.1875 \\
$C_{\sigma}$ & 0.165 \\
$C_{\delta}$ & 0.653 \\
$\sigma_{\max }[\mathrm{psi}]$ & $15.0 \times 10^{3}$ \\
$\delta_{\max }[\mathrm{ft}]$ & 3.5 \\
$E[\mathrm{psi}]$ & $10.0 \times 10^{6}$ \\
$\gamma\left[\mathrm{lbf} / \mathrm{in}^{3}\right]$ & 0.10 \\
$n_{m}$ & 3.75 \\
$n_{g}$ & 3.75 \\
$W_{r}[\mathrm{lbf}]$ & 4500 \\
$W_{n}[\mathrm{lbf}]$ & 7500 \\
$W_{f}(\mathrm{No}$ Pod $)[\mathrm{lbf}]$ & 3000 \\
$W_{f}(\mathrm{With}$ Pod) $[\mathrm{lbf}]$ & 2000 \\
Pod Weight $[\mathrm{lbf}]$ & $500(\times 2)$ \\
$\rho\left[\mathrm{slug} / \mathrm{ft}^{3}\right]$ & 0.0023769 \\
$V_{\infty}[\mathrm{ft} / \mathrm{s}]$ & 287.0 \\
\hline \hline
\end{tabular}

\section{A. Minimizing Induced Drag}

The optimization framework shown in Fig. 5 is used to find the optimum lift distribution, wingspan, and wingstructure weight. For all of the results presented in this paper, this framework was used in conjunction with the SciPy* implementation of the Sequential Least-Squares Programming [58] method. For both Ikhana configurations, the net weight is fixed at $W_{n}=7500 \mathrm{lbf}$, and the wing loading is fixed at 31.831 for the no-pod configuration and 32.101 for the pod configuration. A spar-width constraint of $w_{\max } / c=0.1$ is also imposed. The wingspan $b$ and the Fourier coefficients $B_{n}$ that define the lift distribution are the design variables. However, because the lift distribution is a

${ }^{*}$ docs.scipy.org/doc/scipy/reference/generated/scipy.optimize.minimize.html 
function of an infinite number of Fourier coefficients, the series must be truncated at some finite value of $n$. For the following results, the series was truncated at $n=29$. Constraints are also placed on the lift distribution to ensure that only Fourier coefficients that give an all-positive, spanwise-symmetric lift distribution are considered.

The resulting optimum lift distribution for each configuration is shown in Fig. 8, along with five reference lift distributions labeled $a, b, c, d$, and $e$. Curve $a$ is the elliptic lift distribution. Curve $b$ is Prandtl's 1933 lift distribution [39]. Curves $c$ and $d$ are the optimum lift distributions found by Phillips et al. [48] for the stress-limited design (curve $c$ ) and deflection-limited design (curve $d$ ) of a rectangular wing with fixed wing loading and the weight distribution given by Eqs. (9) and (10). Curve $e$ is the optimum lift distribution found by Taylor and Hunsaker [49] for the stresslimited design of a tapered wing with fixed wing loading, the weight distribution given by Eqs. (9) and (10), and a taper ratio of $R_{T}=0.4$.

Figure 8 shows that the lift distribution that minimizes induced drag for the no-pod configuration is nearly identical to that for the pod configuration and that both lift distributions are noticeably non-elliptic. The Fourier coefficients for both optimum lift distributions are included in Table 2. Note that the magnitude of the Fourier coefficients decreases rapidly as $n$ increases. The same trend is shown in Refs. [51] and [49]. In fact, both lift distributions are primarily dominated by the $n=3$ terms in Eq. (1), with $B_{3}=-0.091066$ for the no-pod configuration and $B_{3}=-0.084530$ for the pod configuration. These values fall between the optimum values of $B_{3}=-0.13564$ and $B_{3}=-0.059716$ found by Phillips et al. [48] for the stress- and deflection-limited designs of a rectangular wing with fixed wing loading.

Figure 8 shows that the analytical solutions for the optimum lift distribution for a rectangular wing (curve $c$ ) and for a wing with taper ratio $R_{T}=0.4$ (curve $e$ ) are nearly identical. As pointed out by Taylor and Hunsaker [49], this suggests that that the taper ratio does not significantly affect the optimum lift distribution. Moreover, the optimum lift distributions for the Ikhana configurations differ slightly from the analytical optimum lift distribution for a tapered wing with $R_{T}=0.4$. Therefore, we can infer that the difference between the optimum lift distributions for the Ikhana configurations and the analytic solutions given by curves $c, d$, and $e$ is likely due to differences in the weight distribution instead of the planform shape. This inference is supported by the sensitivity study for the optimum Ikhana pod configuration shown in the following subsection.

Minimum induced drag is obtained by using the optimum wingspan, wing-structure weight, and lift distribution in Eq. (2). For the no-pod configuration, the optimum wingspan is $b=78.083 \mathrm{ft}$ with a wing-structure weight of $W_{s}=1988.6 \mathrm{lbf}$. Using these values, along with the optimum lift distribution from Fig. 8, the induced drag is $D_{i}=49.213 \mathrm{lbf}$. Therefore, for the no-pod configuration, using the optimum lift distribution allows an increase in wingspan of $18.31 \%$, an increase in wing-structure weight of $97.21 \%$, and results in a reduction in induced drag of $8.93 \%$ over the baseline no-pod configuration with an elliptic lift distribution.

For the pod configuration, the optimum wingspan is $b=77.084 \mathrm{ft}$ with a wing-structure weight of $W_{s}=2013.1$ lbf. When used in Eq. (2), this gives an induced drag of $D_{i}=50.588 \mathrm{lbf}$ when the optimum lift distribution is used. Thus, for the pod configuration, the optimum lift distribution allows an increase in wingspan of $16.79 \%$, an increase in wing-structure weight of $86.32 \%$, and a reduction in induced drag of $7.95 \%$ over the baseline pod configuration with an elliptic lift distribution. Both optimum Ikhana designs are deflection-limited.

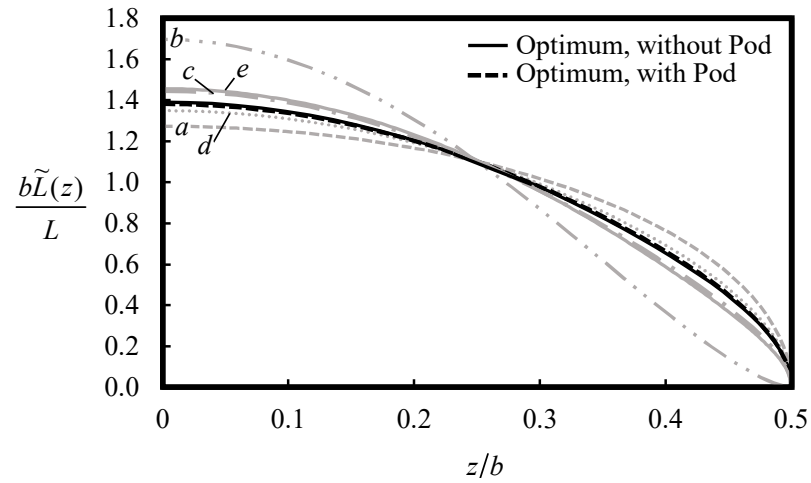

Fig. 8 Solutions for the lift distributions that minimize induced drag for the example no-pod and pod configurations of the NASA Ikhana airframe. 
The wing-structure weight distributions for the baseline Ikhana designs and the optimum designs are shown in Fig. 9. Although Ikhana has a non-rectangular planform and a weight distribution other than Eq. (9), the optimum wing-structure weight for both the no-pod configuration and the pod configuration is just over $26 \%$ of the net weight. This agrees relatively well with the theoretical optimum wing-structure weight of $W_{s}=W_{n} / 4$ found by Phillips et al. [48] for the deflection-limited design of a rectangular wing with the weight distribution given by Eq. (9). For both configurations, the maximum section width-to-chord ratio is less than the constraint of $w_{\max } / c=0.1$. The results of the optimization are summarized in Table 2.

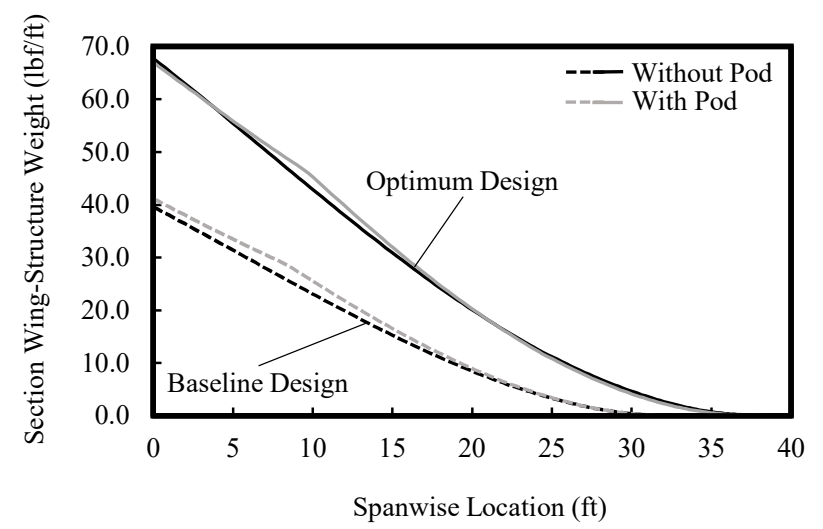

Fig. 9 Wing-structure weight distributions for the baseline design and optimum design of the example no-pod configuration (black) and pod configuration (gray) of the NASA Ikhana airframe.

Table 2 Example optimization results for the NASA Ikhana airframe

\begin{tabular}{lllll}
\hline \hline & \multicolumn{2}{c}{ Without Pod } & \multicolumn{2}{c}{ With Pod } \\
& Baseline & Optimum & Baseline & Optimum \\
\hline$b[\mathrm{ft}]$ & 66 & 78.083 & 66 & 77.084 \\
$S\left[\mathrm{ft}^{2}\right]$ & 267.3 & 298.10 & 267.3 & 296.35 \\
$R_{A}$ & 16.296 & 20.453 & 16.296 & 20.050 \\
$W_{s}[\mathrm{lbf}]$ & 1008.4 & 1988.6 & 1080.5 & 2013.1 \\
$D_{i}[\mathrm{lbf}]$ & 54.040 & 49.213 & 54.959 & 50.588 \\
$w_{\max } / c$ & 0.037602 & 0.072507 & 0.039047 & 0.070664 \\
$B_{3}$ & 0 & -0.091066 & 0 & -0.084530 \\
$B_{5}$ & 0 & $1.6121 \times 10^{-3}$ & 0 & $1.2429 \times 10^{-3}$ \\
$B_{7}$ & 0 & $2.9248 \times 10^{-4}$ & 0 & $2.6259 \times 10^{-4}$ \\
$B_{9}$ & 0 & $-5.1777 \times 10^{-6}$ & 0 & $-3.5980 \times 10^{-5}$ \\
$B_{11}$ & 0 & $1.2718 \times 10^{-5}$ & 0 & $1.1619 \times 10^{-5}$ \\
$B_{13}$ & 0 & $-5.1777 \times 10^{-6}$ & 0 & $-4.7294 \times 10^{-6}$ \\
$B_{15}$ & 0 & $2.3058 \times 10^{-6}$ & 0 & $2.1291 \times 10^{-6}$ \\
$B_{17}$ & 0 & $-1.3044 \times 10^{-6}$ & 0 & $-1.1761 \times 10^{-6}$ \\
$B_{19}$ & 0 & $6.1712 \times 10^{-7}$ & 0 & $5.7982 \times 10^{-7}$ \\
$B_{21}$ & 0 & $-4.8380 \times 10^{-7}$ & 0 & $-4.2720 \times 10^{-7}$ \\
$B_{23}$ & 0 & $1.8249 \times 10^{-7}$ & 0 & $1.6479 \times 10^{-7}$ \\
$B_{25}$ & 0 & $-2.3663 \times 10^{-7}$ & 0 & $-2.1818 \times 10^{-7}$ \\
$B_{27}$ & 0 & $3.9513 \times 10^{-8}$ & 0 & $3.3079 \times 10^{-8}$ \\
$B_{29}$ & 0 & $-1.4703 \times 10^{-7}$ & 0 & $-1.3633 \times 10^{-7}$ \\
\hline \hline & & & & \\
\hline
\end{tabular}


Induced-drag contours around the optimum design for each example Ikhana configuration are shown in Fig. 10 as a function of the design variables $b$ and $B_{3}$. In reality, because the lift distribution is a function of $n$ Fourier coefficients, the design space is more than $n$-dimensonal. However, because the optimum lift distribution for each Ikhana configuration is dominated by $B_{3}$, the effect of the lift distribution on the induced drag is approximated using $B_{3}$ alone. Recall that the wing-structure weight is related to the lift distribution and the wingspan such that as $B_{3}$ decreases, or as wingspan decreases, the wing-structure weight also decreases. Thus, the bottom left regions of the plot correspond to lower-weight designs.

Figure 10 gives some insight into the relative influence of the wingspan, weight, and lift distribution on the induced drag at different points in the design space. For example, for both Ikhana configurations, the induced-drag contours are nearly vertical around the baseline design. This means that around the baseline design, the drag is much more sensitive to changes in wingspan than it is to changes in lift distribution. Because the wing-structure weight typically increases as the wingspan increases, it is more advantageous to increase the wingspan and the weight than to decrease the weight by changing the lift distribution. On the other hand, there are regions in the design space where reducing the weight by changing the lift distribution gives a greater reduction in induced drag than changing the wingspan.

Note that near a wingspan of $66 \mathrm{ft}$, the induced drag contours for both configurations are not smooth. This is because for the range of $B_{3}$ shown, the wing design transitions from stress-limited to deflection-limited near this wingspan. If the wingspan is higher than the wingspan at which this transition occurs, the design is deflection-limited. If the wingspan is lower than the transition wingspan, the design is stress-limited. Thus, although the baseline design is stress-limited, the optimization results in a deflection-limited design for both Ikhana configurations.

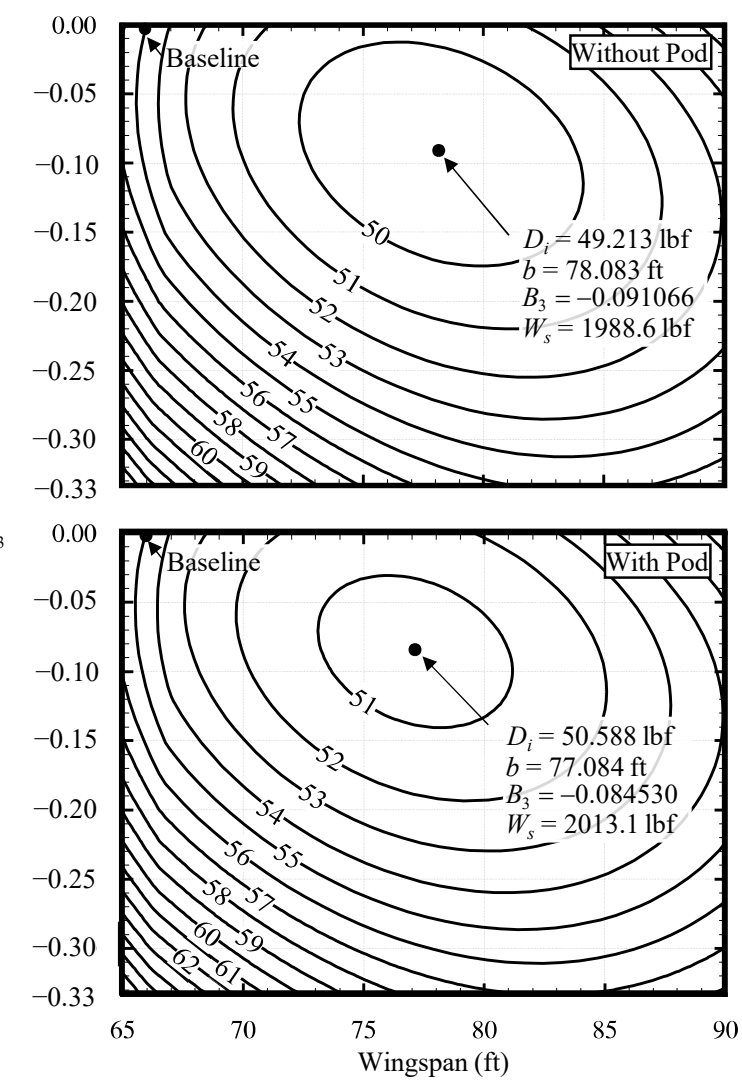

Fig. 10 Induced-drag contours for the example no-pod configuration and pod configuration of the NASA Ikhana airframe. 
The characteristics of the design space depend on the wing configuration, and a figure like Fig. 10 can require more than 100,000 function evaluations. However, using the methods presented in this paper, a visualization of the design space similar to that shown in Fig. 10 can be produced in seconds for a wide range of wing configurations. Understanding of the design space during early design phases can facilitate rapid conceptual optimization and reveal important aspects of the design that cannot be easily seen using high-fidelity methods alone.

\section{B. Sensitivity of Optimum Solution to Design Parameters}

In general, the optimum value for $B_{3}$, the optimum wingspan, and the corresponding wing-structure weight and minimum induced drag depend on the wing-design parameters in Eqs. (2), (4), (5), and (15). Figure 11 shows the percent change in minimum induced drag, optimum wingspan, optimum $B_{3}$, and optimum wing-structure weight as a function of the percent change in pod location, average $S_{b}$, and the parameters $W_{r}, W / S$, and $R_{T}$ for the pod configuration of the NASA Ikhana airframe. Note that the percent change in pod location is measured in percent semispan.

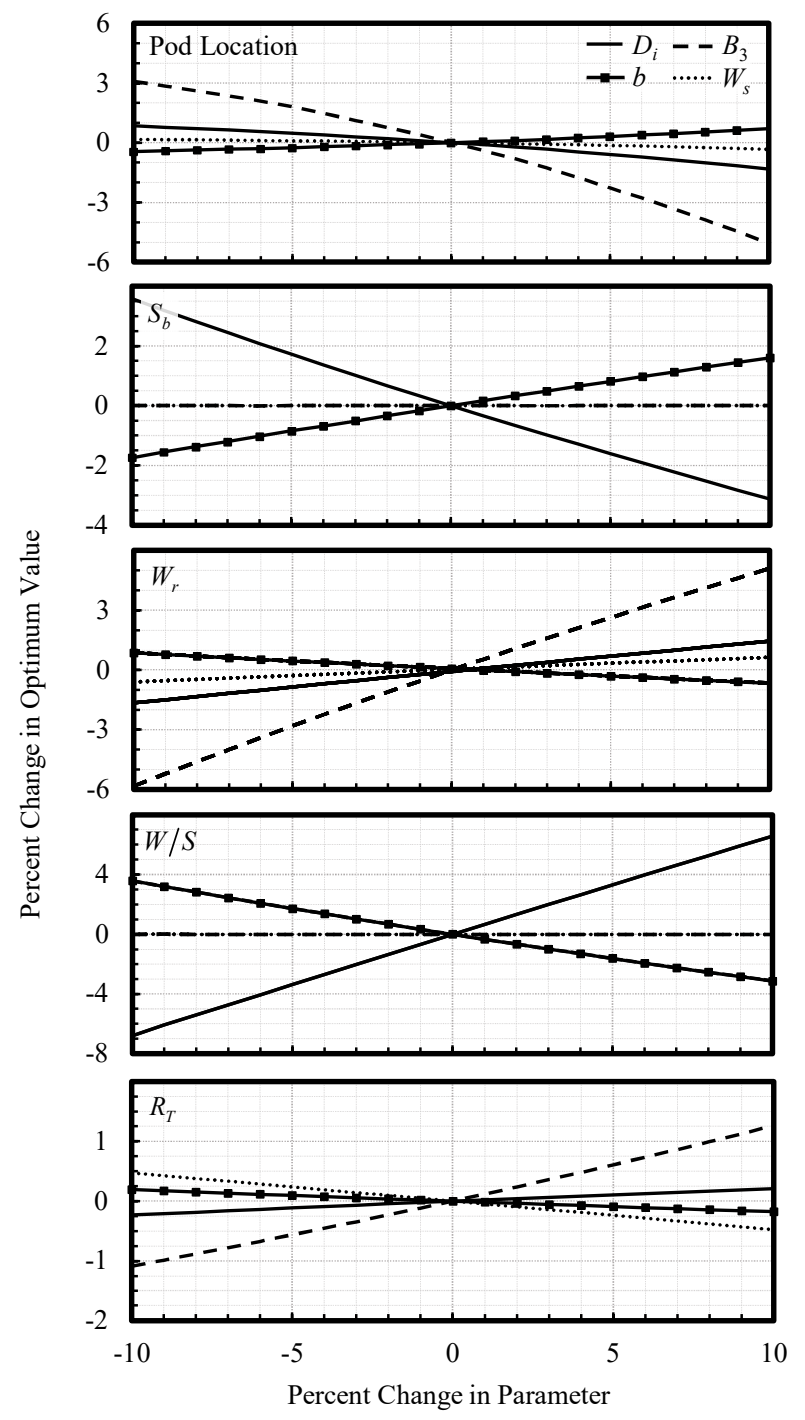

Fig. 11 Percent change in minimum induced drag and optimum wingspan, $B_{3}$, and wing-structure weight with change in pod location and the parameters $S_{b}, W_{r}, W / S$, and $R_{T}$ for the example Ikhana pod configuration. 
Figure 11 shows that the optimum lift distribution, which is characterized by $B_{3}$, is most sensitive to the weight distribution. In particular, the plots for $W_{r}$ and pod location show that as the pod is shifted away from the wing root, or the root weight decreases, the value for $B_{3}$ also decreases. Because $B_{3}$ is negative, a decrease in $B_{3}$ corresponds to a less-elliptic lift distribution, which results in an increase in the wingspan with no change in wing-structure weight. Thus, as the root weight decreases or the pod location is shifted outboard, induced drag decreases. This trend supports the result found by Phillips et al. [47] that the optimum root weight is given by Eq. (10). Whereas the Ikahana configurations shown in Table 1 have a root weight of $W_{r}=4500 \mathrm{lbf}$, Eq. (10) predicts a theoretical optimum root weight close to $W_{r} \approx 3500 \mathrm{lbf}$. Thus, for the Ikhana airframe, we expect to see a decrease in induced drag as weight is shifted away from the root, as shown in Fig. 11. Note that the lift distribution is not sensitive to changes in average $S_{b}$ or $W / S$ and $B_{3}$ only changes by about $\pm 1 \%$ with $\pm 10 \%$ changes in $R_{T}$, which is consistent with the results shown in Fig. 8 and the observation made by Taylor and Hunsaker [49] that the optimum lift distribution is relatively insensitive to the taper ratio.

Figure 11 also shows that the optimum wing-structure weight is nearly independent of all the design parameters shown. In fact, the wing-structure weight does not change at all with changes in average $S_{b}$ and $W / S$, and it changes by less than $\pm 0.65 \%$ with $\pm 10 \%$ changes in pod location, $W_{r}$, and $R_{T}$. This supports the analytic solution found by Phillips et al. [48] and Taylor and Hunsaker [49] that the optimum wing-structure weight for rectangular wings with fixed wing loading and fixed stall speed, and for tapered wings with fixed wing loading, is independent of all other design parameters.

Note that only the optimum wingspan and corresponding induced drag are affected by changes in average $S_{b}$ and $W / S$. For $S_{b}$, this is not surprising because $S_{b}$ is simply a measure of how effectively the wing-structure can support the wing bending moments with as little wing-structure weight as possible. Thus, an increase in $S_{b}$ corresponds to an increase in the efficiency of the wing-structural design, allowing an increase in the wingspan with no corresponding increase in wing-structure weight. It should be emphasized that for the range of $S_{b}$ shown, the optimum design is deflection-limited, which means that $S_{b}$ is inversely proportional to $\gamma$ and directly proportional to $C_{\delta}$, $E$, and $\delta_{\max }$, as shown in Eq. (15). Therefore, the sensitivities shown in Fig. 11 for $S_{b}$ are also characteristic of the sensitivities for $C_{\delta}, E, \delta_{\max }$, and the quantity $1 / \gamma$.

The results in this section show how the methods presented in this paper can be used for design space exploration. In particular, it is shown that these methods can be used to identify the optimum lift distribution, wingspan, and wingstructure weight that minimize induced drag. Because the methods are fast, they can be used to rapidly visualize the coupled aerostructural design space and obtain solution sensitivities to various design parameters. It should be remembered that the results shown here are only valid for the two example configurations of the NASA Ikhana airframe given in Table 1. However, the methods presented in this paper can be used for any unswept planar wing with arbitrary planform and weight distribution to rapidly iterate on possible design concepts.

\section{Conclusions}

Low-fidelity methods are valuable for rapid aerostructural optimization during the conceptual and preliminary design phases. However, most modern aerostructural methods use mid- and high-fidelity solvers, which are better suited for later design phases. Although several analytic and low-fidelity methods exist for aerostructural optimization, the majority are limited in application to wings with specific planforms and weight distributions. Here, a low-fidelity numerical method has been presented that includes more general approximations corresponding to arbitrary planforms and weight distributions. The method uses an iterative solver to determine the wing-structure weight and induced drag for a given lift distribution and wingspan. When implemented in an optimization framework, this solver can be used for rapid design-space exploration and optimization.

Section V shows an example application of the method presented in this paper for minimizing induced drag on two configurations of the NASA Ikhana airframe. A summary of the optimization results, including the optimum wingspans, wing-structure weights, and Fourier coefficients defining the optimum lift distributions are given in Table 2. The optimum lift distribution for both Ikhana configurations is shown in Fig. 8. It has been shown that the optimum wing-structure weight for both Ikhana configurations is in good agreement with the theoretical optimum wing-structure weight. The optimum lift distribution for the Ikhana configurations is very similar to the analytic optimum lift distribution for a rectangular wing with the ideal weight distribution given in Eq. (9).

A visualization of the design space for each Ikhana configuration is shown in Fig. 10. It has been shown that the relative influence of the wingspan, lift distribution, and wing-structure weight depend on the location of the design in the design space. Figure 11 shows the sensitivities of the optimum design values to changes in pod location, proportionality coefficient, root weight, wing loading, and taper ratio for the pod configuration of the Ikhana airframe. 
It has been shown that the optimum wingspan is primarily dependent on the proportionality coefficient and wing loading and that the optimum lift distribution is primarily dependent on the weight distribution. It has also been shown that the optimum wing-structure weight is nearly independent of all other parameters. For the Ikhana configurations considered here, the optimum design allows a wingspan increase of up to $18.31 \%$, an increase in wing-structure weight of up to $97.21 \%$, and a reduction in induced drag of up to $8.93 \%$ over the baseline Ikhana configuration. All results were obtained in a matter of seconds.

It should be remembered that the methods presented here were derived using the assumptions associated with lifting-line theory, including zero sweep and moderate to high aspect ratio. For other wing designs, modifications to these methods may be needed. However, the methods presented here are useful for many practical aircraft configurations. In early design phases, these methods can be used for rapid conceptual optimization and visualization of the design space. These results can provide important insight into the effects of the wing aerodynamic and structural properties and the wing weight distribution on the minimum-induced-drag design.

\section{Acknowledgements}

This material is partially based upon work supported by NASA under Grant No. 80NSSC18K1696 issued by the Aeronautics Research Mission Directorate through the 2018 NASA Fellowship Activity with Nhan Nguyen as the NASA Technical Advisor.

\section{References}

[1] Phillips, W. F., "Lifting-Line Analysis for Twisted Wings and Washout-Optimized Wings," Journal of Aircraft, Vol. 41, No. 1, 2004, pp. 128-136. (doi:10.2514/1.262)

[2] Phillips, W. F., Fugal, S. R., and Spall, R. E., "Minimizing Induced Drag with Wing Twist, Computational-Fluid-Dynamics Validation," Journal of Aircraft, Vol. 43, No. 2, 2006, pp. 437-444. (doi:10.2514/1.15089)

[3] Gallay, S., and Laurendeau, E., "Preliminary-Design Aerodynamic Model for Complex Configurations Using Lifting-Line Coupling Algorithm," Journal of Aircraft, Vol. 53, No. 4, 2016, pp. 1145-1159. (doi:10.2514/1.C033460)

[4] Phillips, W. F., and Hunsaker, D. F., "Lifting-Line Predictions for Induced Drag and Lift in Ground Effect," Journal of Aircraft, Vol. 50, No. 4, 2013, pp. 1226-1233. (doi:10.2514/1.C032152)

[5] Wickenheiser, A., and Garcia, E., "Aerodynamic Modeling of Morphing Wings Using an Extended Lifting-Line Analysis," Journal of Aircraft, Vol. 44, No. 1, 2007, pp. 10-16. (doi:10.2514/1.18323)

[6] Phillips, W. F., and Snyder, D. O., "Modern Adaptation of Prandtl's Classic Lifting-Line Theory," Journal of Aircraft, Vol. 37, No. 4, 2000, pp. 662-670. (doi:10.2514/2.2649)

[7] Rasmussen, M. L., and Smith, D. E., "Lifting-Line Theory for Arbitrarily Shaped Wings," Journal of Aircraft, Vol. 36, No. 2, 1999, pp. 340-348. (doi:10.2514/2.2463)

[8] Bera, R. K., "Some remarks on the solution of the lifting line equation," Journal of Aircraft, Vol. 11, No. 10, 1974, pp. 647648. (doi:10.2514/3.44397)

[9] Prandtl, L., "Tragflügel Theorie," Nachricten von der Gesellschaft der Wissenschaften zu Göttingen, Geschäeftliche Mitteilungen, Klasse, 1918, pp. 451-477.

[10] Prandtl, L., “Applications of Modern Hydrodynamics to Aeronautics,” NACA TR-116, June 1921.

[11] Munk, M. M., "The Minimum Induced Drag of Aerofoils,” NACA TR-12, 1923.

[12] Burdette, D. A., and Martins, J. R. R. A., "Impact of Morphing Trailing Edges on Mission Performance for the Common Research Model," Journal of Aircraft, Vol. 56, No. 1, 2019, pp. 369-384. (doi:10.2514/1.C034967)

[13] Kenway, G. K. W., and Martins, J. R. R. A., "Multipoint High-Fidelity Aerostructural Optimization of a Transport Aircraft Configuration," Journal of Aircraft, Vol. 51, No. 1, 2014, pp. 144-160. (doi:10.2514/1.C032150)

[14] Liem, R. P., Martins, J. R. R. A., and Kenway, G. K. W., "Expected drag minimization for aerodynamic design optimization based on aircraft operational data," Aerospace Science and Technology, Vol. 63, 2017, pp. $344-362$. (doi:10.1016/j.ast.2017.01.006)

[15] Mader, C. A., and Martins, J. R. R. A, "Stability-Constrained Aerodynamic Shape Optimization of Flying Wings," Journal of Aircraft, Vol. 50, No. 5, 2013, pp. 1431-1449. (doi:10.2514/1.C031956)

[16] Zhang, Z. J., Khosravi, S., and Zingg, D. W., "High-fidelity aerostructural optimization with integrated geometry parameterization and mesh movement," Structural and Multidisciplinary Optimization, Vol. 55, 2017, pp. 1217-1235. (doi:10.1007/s00158-016-1562-7) 
[17] James, K. A., Kennedy, G. J., and Martins, J. R. R. A., "Concurrent aerostructural topology optimization of a wing box," Computers and Structures, Vol. 134, 2014, pp. 1-17. (doi:10.1016/j.compstruc.2013.12.007)

[18] Jansen, P. W., Perez, R. E., and Martins, J. R. R. A., “Aerostructural Optimization of Nonplanar Lifting Surfaces,” Journal of Aircraft, Vol. 47, No. 5, 2010, pp. 1490-1503. (doi: 10.2514/1.44727)

[19] Ting, E., Chaparro, D., Nguyen, N., and Fujiwara, G. E. C., "Optimization of Variable-Camber Continuous Trailing-Edge Flap Configuration for Drag Reduction,” Journal of Aircraft, Vol. 55, No. 6, 2018, pp. 2217-2239. (doi:10.2514/1.C034810)

[20] Lundry, J. L., "Minimum Swept-Wing Induced Drag with Constraints on Lift and Pitching Moment," Journal of Aircraft, Vol. 4, 1967, pp. 73-74. (doi:10.2514/3.43797)

[21] Lissaman, P. B. S., and Lundry, J. L., “A Numerical Solution for the Minimum Induced Drag of Nonplanar Wings,” Journal of Aircraft, Vol. 5, 1968, pp. 17-21. (doi:10.2514/3.43901)

[22] Ashenberg, J., and Weihsradius, D., "Minimum Induced Drag of Wings with Curved Planform," Journal of Aircraft, Vol. 21, 1984, pp. 89-91. (doi:10.2514/3.56733)

[23] Rokhsaz, K., "Effect of Viscous Drag on Optimum Spanwise Lift Distribution,” Journal of Aircraft, Vol. 30, 1993, pp. 152154. (doi:10.2514/3.46328)

[24] Demasi, L., "Induced Drag Minimization: A Variational Approach Using the Acceleration Potential," Journal of Aircraft, Vol. 43, 2006, pp. 669-680. (doi:10.2514/1.15982)

[25] Demasi, L., "Erratum on Induced Drag Minimization: A Variational Approach Using the Acceleration Potential," Journal of Aircraft, Vol. 43, 2006, p. 1247. (doi:10.2514/1.26648)

[26] Demasi, L., "Investigation on the Conditions of Minimum Induced Drag of Closed Wing Systems and C-Wings," Journal of Aircraft, Vol. 44, 2007, pp. 81-99. (doi:10.2514/1.21884)

[27] Demasi, L., Dipace, A., Monegato, G., and Cavallaro, R., "Invariant Formulation for the Minimum Induced Drag Conditions of Nonplanar Wing Systems," AIAA Journal, Vol. 52, 2014, pp. 2223-2240. (doi:10.2514/1.J052837)

[28] Demasi, L., Monegato, G., and Cavallaro, R., "Minimum Induced Drag Theorems for Multiwing Systems," AIAA Journal, Vol. 55, 2017, pp. 3266-3287. (doi:10.2514/1.J055652)

[29] Gray, W. L., and Schenk, K. M., "A Method for Calculating the Subsonic Steady-State Loading on an Airplane with a Wing of Arbitrary Planform and Stiffness," NACA TR-3030, December, 1953.

[30] Craig, A. P., and McLean, D. J., "Spanload Optimization for Strength Designed Lifting Surfaces," AIAA 88-2512, 6th Applied Aerodynamics Conference, Williamsburg, Virginia, 5-8 June 1988.

[31] Haftka, R. T., "Optimization of Flexible Wing Structures Subject to Strength and Induced Drag Constraints," AIAA Journal, Vol. 14, No. 8, 1977, pp. 1101-1106. (doi: 10.2514/3.7400)

[32] Grossman, B., Gurdal, Z., Strauch, G. J., Eppard, W. M., and Haftka, R. T., "Integrated Aerodynamic/Structural Design of a Sailplane Wing,” Journal of Aircraft, Vol. 25, No. 9, 1988, pp. 855-860. (doi: 10.2514/3.45670)

[33] Wakayama, S., and Kroo, I. M., "Subsonic Wing Planform Design Using Multidisciplinary Optimization," Journal of Aircraft, Vol. 32, No. 4, 1995, pp. 746-753. (doi: 10.2514/3.46786)

[34] Calderon, D. E., Cooper, J. E., Lowenberg, M., and Neild, S. A., "On the Effect of Including Geometric Nonlinearity in the Sizing of a Wing," AIAA 2018-1680, 2018 AIAA/ASCE/AHS/ASC Structures, Structural Dynamics, and Materials Conference, Kissimmee, Florida, 8-12 January, 2018.

[35] Iglesias, S., and Mason, W. H., "Optimum Spanloads Incorporating Wing Structural Weight," AIAA 2001-5234, 1st Aircraft, Technology Integration, and Operations Forum, Los Angeles, California, 16-18 October 2001.

[36] Wroblewski, G. E., and Ansell, P. J., "Prediction and Experimental Evaluation of Planar Wing Spanloads for Minimum Drag," Journal of Aircraft, Vol. 54, 2017, pp. 1664-1674. (doi:10.2514/1.C034156)

[37] McGeer, T., "Wing Design for Minimum Drag with Practical Constraints," Journal of Aircraft, Vol. 21, 1984, pp. 879-886. (doi:10.2514/3.45058)

[38] Gopalarathnam, A., and Norris, R. K., "Ideal Lift Distributions and Flap Angles for Adaptive Wings," Journal of Aircraft, Vol. 46, No. 2, 2009, pp. 562-571. (doi: 10.2514/1.38713)

[39] Prandtl, L., "Über Tragflügel kleinsten induzierten Widerstandes," Zeitschrift für Flugtechnik und Motorluftschiffahrt, Vol. 24, No. 11, 1933, pp. 305-306.

[40] Jones, R. T., "The Spanwise Distribution of Lift for Minimum Induced Drag of Wings Having a Given Lift and a Given Bending Moment," NACA TR-2249, December 1950.

[41] Pate, D. J., and German, B. J., "Lift Distributions for Minimum Induced Drag with Generalized Bending Moment Constraints," Journal of Aircraft, Vol. 50, 2013, pp. 936-946. (doi:10.2514/1.C032074)

[42] DeYoung, J., "Minimization Theory of Induced Drag Subject to Constraint Conditions," NASA CR-3140, June 1979.

[43] Jones, R. T., and Lasinski, T. A., "Effect of Winglets on the Induced Drag of Ideal Wing Shapes," NASA TM-81230, Sept. 1980. 
[44] Klein, A., and Viswanathan, S. P., "Minimum Induced Drag of Wings with Given Lift and Root-Bending Moment," Zeitschrift fur Angewandte Mathematik und Physik, Vol. 24, 1973, pp. 886-892.

[45] Klein, A., and Viswanathan, S. P., "Approximate Solution for Minimum Induced Drag of Wings with Given Structural Weight," Journal of Aircraft, Vol. 12, No. 2, 1975, pp. 124-126. (doi:10.2514/3.44425)

[46] Löbert, G., "Spanwise Lift Distribution for Forward- and Aft-Swept Wings in Comparison to the Optimum Distribution Form," Journal of Aircraft, Vol. 18, No. 6, 1981, pp. 496-498. (doi:10.2514/3.44717)

[47] Phillips, W. F., Hunsaker, D. F., and Joo, J. J., "Minimizing Induced Drag with Lift Distribution and Wingspan," Journal of Aircraft, Vol. 56, No. 2, 2019, pp. 431-441. (doi:10.2514/1.C035027)

[48] Phillips, W. F., Hunsaker, D. F., and Taylor, J. D., "Minimizing Induced Drag with Weight Distribution, Lift Distribution, Wingspan, and Wing-Structure Weight,” AIAA 2019-3349, AIAA Aviation 2019 Forum, Dallas, Texas, 17-21 June 2019. (doi: 10.2514/6.2019-3349)

[49] Taylor, J. D., and Hunsaker, D. F., "Minimum Induced Drag for Tapered Wings Including Structural Constraints," Journal of Aircraft, To Be Published, Preprint Available. (doi:10.2514/1.C035757)

[50] Phillips, W. F., and Hunsaker, D. f., "Designing Wing Twist or Planform Distributions for Specified Lift Distributions," Journal of Aircraft, Vol. 56, No. 2, 2019, pp. 847-849. (doi:10.2514/1.C035206)

[51] Taylor, J. D., Hunsaker, D. F., and Joo, J. J., "Numerical Algorithm for Wing-Structure Design,” AIAA 2018-1050, 2018 AIAA Aerospace Sciences Meeting, Kissimmee, Florida, 8-12 January 2018. (doi: 10.2514/6.2018-1050)

[52] Merlin, P. W., “'Don't Fear the Reaper,' Ikhana: Unmanned Aircraft System Western States Fire Missions,” Monographs in Aerospace History, Vol 44, National Aeronautics and Space Administration, NASA SP-2009-4544, 2009, pp. 1-18.

[53] Cobleigh, B. R., "Ikhana: A NASA UAS Supporting Long Duration Earth Science Missions,” NASA TM2007-214614, March 2007.

[54] Ko, W. L., Richards, W. L., and Fleischer, V. T., "Applications of Ko Displacement Theory to the Deformed Shape Predictions of the Doubly-Tapered Ikhana Wing," NASA TP-2009-214652, October 2009.

[55] "Ikhana: Unmanned Science and Research Aircraft System," NASA FS-097-DFRC, 2014.

[56] Glauert, H., The Elements of Aerofoil and Airscrew Theory, Cambridge University Press, London, 1926.

[57] Phillips, W. F., "Incompressible Flow over Finite Wings," Mechanics of Flight, 2nd ed., Wiley, Hoboken, NJ, 2010, pp. 4694.

[58] Kraft, D. “A software package for sequential quadratic programming," DLR German Aerospace Center - Institute for Flight Mechanics, DFVLR-FB 88-28, Koln, Germany, 1988. 